\title{
Gebt den Frauen die Macht!
}

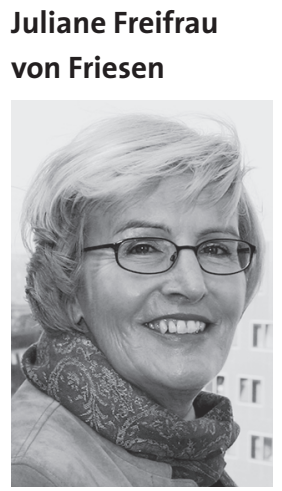

Senatorin a.D., Personal- und Unternehmensberaterin, Berlin
Diese Forderung stellte Maria von Welser, Direktorin des NDR Landesfunkhauses Hamburg, in ihrem Vortrag am 25. Januar vor den Gästen des LadiesNeujahrsempfangs der FDP-Bundestagsfraktion auf. Zuvor hatte schon Cornelia Pieper in ihrer Begrüßung als Jahresmotto „Gebt den Frauen das Geld“ verkündet und dies damit begründet, dass Frauen mit Geld sinn- und verantwortungsvoller umgingen als Männer, und das in aller Welt.

Die zahlreich in der Mittagszeit in die Deutsche Parlamentarische Gesellschaft gekommenen Damen aus Politik, Wirtschaft und Gesellschaft stimmten den Rednerinnen uneingeschränkt zu. Von Welser wies darauf hin, dass Frauen zwar einen Anteil von 52 Prozent an der Bevölkerung weltweit hätten, aber von 193 Staaten nur acht aktuell von Frauen geführt würden. Ändern könne man daran nur etwas, wenn Frauen sich verstärkt einmischen und mitreden würden. Sie zitierte in diesem Zusammenhang ein Sprichwort aus ihrer bayerischen Heimat: „Vom Denken können's die Leut' nicht wissen, sagen müssen wir's ihnen!“
Den heftigen Schlussbeifall bekam sie unter anderem von der stellvertretenden Fraktionsvorsitzenden der FDP im Deutschen Bundestag Sabine Leutheusser-Schnarrenberger und den Parteifreundinnen Irmgard Schwaetzer, Cornelia SchmalzJacobsen, Mieke Senftleben sowie Gisela Wild, Hamburger Anwältin und zugleich erste LibertaPreisträgerin. Außerdem unter den ausschließlich weiblichen Gästen: Anwältin und Buchautorin Martina Haas, Ärztin und Unternehmerin Mercedes Hillen, Professorin und China Gate-Chefin Yu Zhang, die Leiterin der Antidiskriminierungsstelle des Bundes Martina Köppen sowie die neue Präsidentin des Verbandes deutscher Unternehmerinnen Petra Ledendecker und die Präsidentin des Deutschen Juristinnenbundes Jutta Wagner. Die Fahne der Frauen schon von Amts wegen hoch hielten Marlies Brouwers, Deutscher Frauenrat, und Juliane von Friesen, Landesfrauenrat Berlin.

\section{Neue Pressemitteilungen und Stellungnahmen}

\author{
http://www.djb.de/stellungnahmen-und-pressemitteilungen/
}

\section{Pressemitteilungen}

08-07 Equal Pay Day am 15. April 2008. April 2008.

08-06 BVerfG-Urteil ist auch bei Verpflichtung des Kindes zum Umgang mit einem Elternteil zu beachten. April 2008.

08-05 djb warnt vor einem Betreuungsgeld. Februar 2008.

\section{Stellungnahmen}

08-11 Stellungnahme zum Antrag der Fraktion Bündnis 90/ Die Grünen, Deutscher Bundestag, Drucksache 16/5279, Stand 9. Mai 2007, „Quote für Aufsichtsratsgremien börsennotierter Unternehmen einführen?“. April 2008.

08-10 Stellungnahme zum Entwurf eines Gesetzes zur Änderung der Bundesnotarordnung (Neuregelung des $\mathrm{Zu}$ gangs zum Anwaltsnotariat) (BNotO-E) vom 16. Februar 2007 Drucksache 895/06 (Beschluss). April 2008.

08-09 Stellungnahme zum Entwurf eines Gesetzes zur Modernisierung des Vergaberechts des Bundeswirtschaftsministeriums BMWi I B 3-26 05 13/1 (Stand 3. März 2008 - Anhörung im Bundeswirtschaftsministerium am 8. April 2008). April 2008.
08-08 Stellungnahme zum Entwurf eines Gesetzes zur Förderung von Kindern unter drei Jahren in Tageseinrichtungen und in der Kindertagespflege (Kinderförderungsgesetz - KiFöG). April 2008.

08-07 Stellungnahme zum Referentenentwurf für ein Gesetz zur Strukturreform des Versorgungsausgleichs (VAStrRefG-RefE) vom 12. Februar 2008. März 2008.

08-06 Stellungnahme zum Referentenentwurf zur Änderung des Bundeselterngeld- und Elternzeitgesetzes. März 2008.

08-05 Richtlinienumsetzung Gemeinschaftsrecht - Art. 4 und 21 der Richtlinie 2006/54/EG. Brief an die Bundesministerinnen Zypries und von der Leyen. März 2008.

08-04 Stellungnahme zum Berliner Vergabegesetz anlässlich der Anhörung des Ausschusses für Wirtschaft, Technologie und Frauen im Abgeordnetenhaus von Berlin am Montag, den 25. Februar 2008. Februar 2008.

08-03 Stellungnahme anlässlich der Fachtagung der Bundestagsfraktion von Bündnis 90/Die Grünen „Vergaberecht reformieren - Rechtssicherheit schaffen " am 18. Februar 2008 in Berlin. Februar 2008. 